\title{
Sobre la tradició catalana del Tristany de Leonís i un nou testimoni fragmentari* Joan Santanach Suñol
}

\section{De lectors i traduccions}

La literatura catalana medieval, i especialment la narrativa, és des dels orígens deutora de la matèria de Bretanya. Encara que no en exclusiva, ni sovint tampoc com a referent més productiu, els elements propis de la literatura artúrica formaven part del bagatge cultural dels escriptors en Ilengua catalana. Els esments d'herois cavallerescos són presents ja en l'obra de trobadors catalans, i és prou coneguda la influència de l'univers artúric en els textos historiogràfics.' Bernat Desclot, a la seva crònica, escrita entre els anys 1280-1288, fa un retrat de Pere el Gran, el principal personatge del llibre, que no té res a envejar al de qualsevol heroi novellesc. Val a dir que el rei històric va protagonitzar aventures tan singulars i arriscades com el desafiament de Bordeus, que li oferien material de primera qualitat per construir el personatge literari. Això no obstant, és innegable l'habilitat de Desclot a l'hora de recrear el viatge del rei a través de territoris hostils i de dotar-lo d'alè literari; altrament, hauria estat impensable que, gairebé dos segles més tard,

\footnotetext{
* Aquest treball forma part del projecte de recerca co-

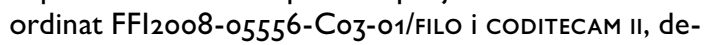
senvolupat al Centre de Documentació Ramon Llull de la Univ. de Barcelona i dins del Grup de Recerca Consolidat SGR «Literatura i cultura a la baixa Edat Mitjana». Voldria agrair a Eulàlia Duran, Anna Gudayol, Amadeu J. Soberanas i Susanna Vela l'interès amb què han atès les consultes que els he fet sobre els manuscrits tristanians. Qui signa aquestes ratlles té en preparació, a la collecció Els Nostres Clàssics de l'Editorial Barcino, una edició dels diversos fragments del Tristany de Leonís conservats en català.

1. Per als ressons artúrics en la literatura autòctona són encara útils Entwistle (1925), Lida de Malkiel (1959) i Bohigas (1982).
}

l'anònim autor del Curial e Güelfa incorporés el personatge del rei Pere bastit pel cronista a la seva novella -és a dir, en una narració ara ja plenament fictícia- i li fes reviure els fets de Bordeus en el torneig de Melú.

Capítols després d'haver relatat el famós desafiament, Desclot posa en boca de Pere el Gran una afirmació que és ben poc probable que el rei històric hagués formulat mai, i menys tenint en compte que l'exèrcit francès era a punt d'envair el Principat, però que és molt reveladora de l'esperit cavalleresc de què volia imbuir el seu personatge literari:

jo, barons, no son cor [-sinó] un cavaller e, entre els altres, si em pot romanir lo cavall e les armes, aitan cuit [=desitjo] viure de cavalleria com nengú que hi sia, mas no seria bon cuit [=desig] ne bon pensament aquest a vosaltres. (Cingolani 2010: 388)

Fa dir al monarca que, si no fos per la seva responsabilitat envers els súbdits, prescindiria ben de gust dels honors que li corresponen com a rei, i de les obligacions que el càrrec comporta, a canvi de poder viure com un cavaller errant més. ${ }^{2}$ No és gens sorprenent, per tant, que pocs anys més tard Ramon Muntaner, que coneixia bé l'obra del seu predecessor Desclot, el comparés en la seva crònica, iniciada l'any 1325, amb el mateix rei Artur, una consideració que, a més, atribueix al seu màxim enemic, Carles d'Anjou; segons Muntaner, el rei Carles «sabia lo cor del rei En Pere, que era lo mellor cavaller del món, e que menava ab si sos bons cavallers de sa terra, que anc lo rei Artús no hac a la Taula Redona.» (Cap. LXVl; Casacuberta 1927-52: II, 6)

2. Per a una lectura interpretativa dels fets narrats, i dels silenciats, a la crònica, Cingolani (2006). 
En d'altres casos els estímuls depenen menys d'influències generals i es poden circumscriure a passatges i fonts concrets. Aquest fóra el cas d'un dels episodis cronístics més coneguts, narrat tant per Desclot com per Muntaner, encara que amb variants. Em refereixo al de l'engendrament del futur Jaume el Conqueridor, en el qual es barregen motius folklòrics, com és el de la substitució de l'amant, amb d'altres de literaris. En aquest darrer àmbit cal remarcar que l'episodi en qüestió, tal com va assenyalar Pere Bohigas fa gairebé cinquanta anys, i Josep Pujol ha confirmat darrerament amb proves textuals, presenta reminiscències de la concepció del cavaller Galaad, fruit de la unió entre Lancelot i la filla del rei Pellés, procedent del Lancelot en prose. ${ }^{3}$ Maria de Montpeller, davant la manca d'interès del seu marit, Pere el Catòlic, a tenir amb ella cap mena de contacte, inclosos els sexuals, ordeix un estratagema per ocupar el lloc d'una de les amants del rei sense que aquest se n'adoni i engendrar, així, el desitjat hereu. L'encontre té lloc a les fosques i no és fins que ella està segura d'haver concebut un fill que es dóna a conèixer al rei i li confessa que ho ha fet no «per nulla malvestat ne per negun malvat desig que jo hagués, mas per tal que de vós e de mi eixís fruit qui plagués a Déu e qui fos hereu de vostre regne» (Cap. Iv; Cingolani 2010:67).

L'estratègia d'ocupació del llit de l'amant inapetent és la mateixa que va donar lloc a l'engendrament de Galaad, i els motius de les futures mares són igualment nobles i lloables: si l'objectiu de Maria és tenir un hereu que durà a terme proeses agradables a Déu, la filla del rei Pellés sap d'avançada que el seu fill intervindrà en l'alta missió de cercar el sant Graal, i que serà ell qui la completarà.

Tampoc Ramon Llull no s'escapa de la influència de la matèria de Bretanya. En aquest sentit, és ben significatiu que el primer text que va escriure amb voluntat d'aproximar-se a la literatura romànica, de la qual poc abans, al famós capítol 118 del Llibre de contemplació, havia abjurat, fos precisament d'inspiració cavalleresca. En efecte,

3. Vegeu Bohigas (1982): 278-81); Riquer (1984: I, 434-7, 464-6), i Pujol (2002a: 412). és en aquest àmbit, i no pas en el propi de tractats doctrinals o penitencials, que s'ha de buscar el model de la narració que trobem al pròleg del Llibre de l'orde de cavalleria. Aquest breu relat, datable vers els anys 1274-1276, és el primer text d'inspiració cavalleresca escrit en català. En el context del tractat lullià el pròleg narratiu, que relata l'encontre d'un ermità i un jove escuder, no té altra funció que la de captatio benevolentiæ per conduir el lector vers el contingut doctrinal recoIlit als capítols que segueixen. Això no va impedir, però, que Joanot Martorell se'n servís a l'inici del seu Tirant lo Blanc.4

En l'obra de Llull el model cavalleresc va tornar a ser ben productiu, aquesta vegada amb voluntat desacomplexadament polèmica, en el Romanç d'Evast e Blaquerna, enllestit a Montpeller vers l'any 1283. El mateix títol del llibre, que el qualifica de romanç, evidencia que es tracta d'una proposta alternativa ben deliberada al gènere del roman artúric. No en va la conveniència que s'hi exposa d'amar, servir i lloar Déu rarament coincideix amb els valors més materials propis de bona part de la narrativa cavalleresca. L'esmena lulliana, doncs, afecta tot el conjunt de l'obra, per bé que és sobretot a l'inici del periple vital del virtuós protagonista, una vegada ha abandonat la casa paterna i cerca un lloc adient per convertir-lo en el seu ermitatge, lluny del brogit mundà, que es narren episodis en què es planteja una clara correcció d'un dels tòpics més habituals del gènere, com són els encontres en plena forest de cavallers errants. En aquests capítols Blaquerna es creua amb cavallers, donzelles i altres personatges propis de la narrativa artúrica que el forcen a intervenir en els seus afers per tal de posar de manifest l'errònia escala de valors que en guia les actuacions. És aleshores que el personatge s'erigeix en contrafigura del cavaller errant, ja que, en Iloc d'enfrontar-se a d'altres cavallers amb una bona muntura i convenientment armat, ho fa sols amb la força dels seus arguments, malgrat tot tan poderosos que obliguen els rivals a acceptar la seva victòria inapellable.5 Així, si el pròleg

4. Per al Llibre de l'orde de cavalleria, vegeu Soler (1988), com també Riquer (1984: I, 246-53).

5. Per al Blaquerna, vegeu Soler \& Santanach (2009), com 


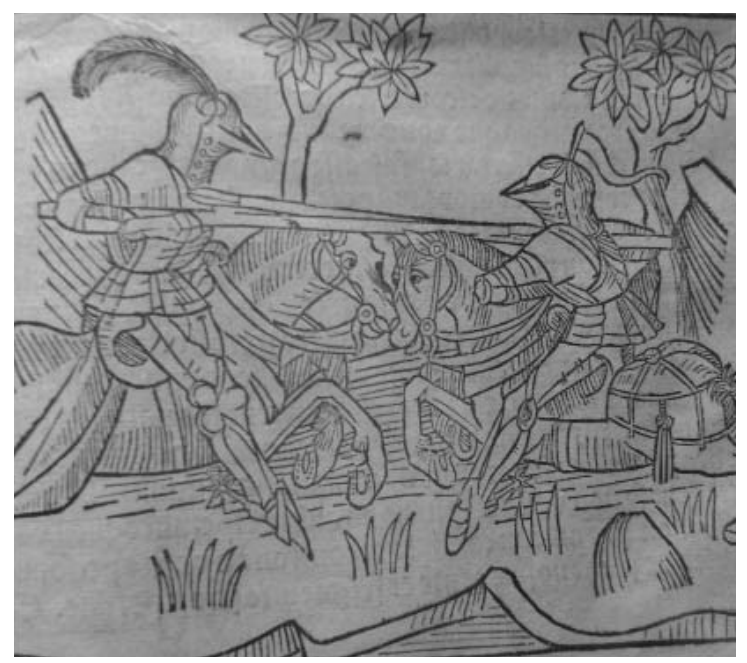

Illustració gravada sobre fusta d'un duel cavalleresc (Tristany en prosa, París, c. 1500).

del Llibre de l'orde de cavalleria posava de manifest la utilitat d'emprar un gènere com el roman per captar l'atenció dels lectors cortesans als quals Llull s'adreçava, la contraproposta del Blaquerna fa evident que, si més no en aquests mateixos estaments, el gènere havia penetrat prou perquè tingués sentit l'esmena a la totalitat que constituïa el text lullià.

La presència d'elements de procedència cavalleresca es manté al llarg dels segles XIV i Xv, i té un dels seus punts culminants en les dues grans novelles del xv -les ja citades Curial i Tirant-, inclosos esments explíits a episodis i personatges bretons. Aquests esments, això no obstant, constitueixen sols la punta de l'iceberg del complex tramat artúric que les informa. ${ }^{6}$ No és sobrer recordar, sobre aquesta qüestió, el reconeixement explícit que es fa del model al pròleg del llibre segon del Curial, precisament el llibre en què es narren les aventures de Curial com a cavaller errant i en el curs del qual el protagonista de la novella esdevé company d'armes del rei Pere el Gran. S'hi mencionen els trasllats catalans del Lancelot i del Tristany i, encara, l'anònim autor es permet formular-hi unes conegudes disquisicions sobre la traducció del francès chevalier errant:

també, entre altres, Riquer (1984: I, 277-80) i Bonner \& Badia (1988: 132).

6. Per al Curial, vegeu sobretot l'anotació de Badia \& Torró (en premsa). Per al Tirant, vegeu Ramos (1995) i Pujol (2002a i 2002b: esp. 40-6 i 187-90).
En aquest libre se fa menció de cavallers errants, jatsia que és mal dit «errants», car deu hom dir «caminants». «Erre» és vocable francès e vol dir «camí», e «errar» vol dir «caminar». Emperò yo vull seguir la manera d'aquells cathalans qui trasladaren los libres de Tristany e de Lançalot, e tornaren-los de lengua francesa en lengua cathalana, e tots temps digueren «cavallers errants». (Aramon i Serra 1930-33: II, 7)

Al costat de la presència, o potser hauríem de dir del rerefons, implícit de la matèria de Bretanya, no s'ha de perdre de vista que al sud de les Corberes també hi va haver obra original en què es reprenien situacions, llocs i personatges propis de l'univers artúric. De nou, el marc cronològic en què se situen és ampli, malgrat que la llista no sigui extensa: abraça des del Jaufré, escrit en octosíllabs apariats occitans per un autor desconegut que, això sí, s'adreçava a Jaume I, fins al mutilat incunable de la Tragèdia de mossèn Gras, de 1496, en què es recrea la Mort le roi Artur d'acord amb els gustos sentimentals de final del $x v$. Entre els títols que es van produir al llarg dels més de dos-cents anys que separen aquests dos, s'ha d'esmentar $L a$ faula del solleric Guillem de Torroella; s'hi conta com el protagonista de la narració és conduït per una balena, que ell ha pres per un escull, fins a Sicília, on una vella tradició situava el rei Artur, exiliat després de la batalla de Salisbury. Allà, el mític monarca en persona li fa prendre consciència de la decadència en què es troben els valors cavallerescos; amb aquestes revelacions, Guillem ja pot tornar a Mallorca i assajar de reconduir la situació. El text finalitza, com no podia ser altrament, amb el feliç retorn de Guillem a Mallorca, muntat de nou al llom de la balena.

Més enllà de la vella discussió sobre la data en què s'ha de situar la penetració en els territoris de parla catalana de la literatura nascuda en terres d'oïl, i de la mateixa amplitud del coneixement d'aquesta literatura,? els paràgrafs anteriors evi-

7. La cronologia de la penetració a l'antiga Corona d'Aragó de la literatura artúrica produïda en francès s'ha basat sovint en la controvertida datació de l'Ensenhamen de Guerau de Cabrera; per a aquesta qüestió, a més de la bibliografia esmentada a la n.1, vegeu, entre altres, Rubió i Balaguer (1984: 41-2, 169-71); Riquer (1984: I, 56-66) i Cingolani (1992-93). 
dencien fins a quin punt des del darrer quart del segle XIII hi havia una circulació efectiva, almenys en cercles propers a la cort, de textos cavallerescos francesos. També sembla molt probable que aquesta circulació es produís majoritàriament en la llengua original de les obres, i no pas per mitjà de traduccions. Sens dubte va ser així en els primers temps, i la preeminència de les versions en francès es degué mantenir fins més endavant. En aquest sentit, és significatiu que la primera notícia que tenim inequívocament identificable amb una versió en català d'un text artúric francès se situï en un moment tan tardà com el 1362; en aquesta data Pere el Cerimoniós demanava des de València que li fessin arribar «lo libre de Lançalot qui es escrit en lengua catalana e en pergami, e lo cual lo duch primogenit nostre tenie l'altre die en Barchinona.»

Cap de les notícies anteriors relatives al pas de la matèria de Bretanya per terres de l'antiga Corona d'Aragó no especifica que es tracti de textos en la llengua pròpia: ni s'indica en els encàrrecs que el mateix rei Pere havia fet de sengles còpies del Lancelot, el 8 de setembre de 1339 i el 17 d'abril de 1346, ni tampoc es fa cap esment a la llengua en què era escrit «lo romanc de tristayn» recollit en l'inventari de béns del mercader valencià Joan de Mitjavila, datat el 2 de desembre de $1331 .{ }^{8}$ Menciono aquests dos exemples, entre altres que podria citar, perquè s'ha plantejat que podien constituir les primeres referències a còpies catalanes d'aquests títols. ${ }^{9}$ Tal com deia, això no obstant, les notícies sobre trasllats catalans de textos artúrics francesos no són en cap cas anteriors als anys seixanta del segle XIV. Si més no, les que n'identifiquen explícitament la llengua o aporten dades que ens permeten inferir que es tracta en efecte de trasllats en pla català.

De la traducció del Lancelot, ja s'ha indicat que el primer esment que en tenim és del 1362, concretament del 17 de febrer, en què el rei Pere demanava que li fessin arribar la versió catalana de l'obra. Aquesta primera carta del Cerimoniós

8. Rubió i Lluch (1908-21: I, cV, 119-20, i cXXVII, 135-6); i Mas (1915-16: 240).

9. Vegeu Duran (1917a: 314 i 316): Rubió i Lluch (1908-21: II, 201 n.), i Bohigas (1982: 284-5). va tenir poc efecte, de manera que un mes més tard, el 16 de març, sense dissimular gens el seu enuig, el rei tornava a ordenar que li fessin arribar la còpia reclamada, que l'infant Joan tenia a Barcelona.10 D'aquesta traducció, ens n'han arribat únicament dos fragments, els quals, quan se'n va donar notícia, pertanyien a dues biblioteques privades; no consta que hagin estat consultats en data recent.11 En canvi, de la Questa o Història del sant Graal en llengua catalana se n'ha conservat una còpia completa, al ms. I 79 Sup. de la Biblioteca Ambrosiana de Milà, al colofó de la qual llegim que «Aqast lebre es d'en .G. Rexach lo qual l'a escrit hi acabat dimecras a xvi yorns de mayg de l'any .m.ccc $|x \times x\rangle.\left(\right.$ f. 130 $\left.{ }^{v b}\right){ }^{12}$ Finalment, per disposar d'una primera referència datada d'un text català del Tristany de Leonís caldrà esperar encara uns quaranta anys: l'any 1422 ens consta que Berenguer de Copons, senyor de Llors, en posseïa un exemplar, tot i que aleshores ja era fragmentari. D'acord amb el que s'indica a l'inventari dels seus béns, al darrer full d'un volum que contenia precisament la traducció catalana de la Història del sant Graal s'hi podia llegir la frase «per ço que no ploras car nol podie acadar, e com Merli viu l'infant», la qual no es correspon pas amb l'èxplicit de la Història, sinó amb el següent passatge del Tristany:

E la donçella se girà e vench a Merlí ab l'infant, que tenie en son bras. E avie-li mesa la sua mamella e.l quex, per ço que no ploràs, car no.l podie aquadar per la fam que avie. E com Merlí viu l'infant tant bé format dix als cavalyers qui ab ell heren: -Què us par dels dos cavallyers malvats que aytal infant com aquest volien destrohir? 13

Com en el cas del Lancelot, del Tristany català no se n'ha conservat cap versió completa, sinó tan sols diversos fragments esparsos. D'altra banda, no cal dir que l'existència de traduccions

\footnotetext{
10. Vegeu Rubió i Lluch (1908-21: I, CCIV i CCV, 201-2). 11. Rubió i Lluch (1903) i Bohigas (1967).

12. Vegeu-ne l'edició en Crescini \& Todesco (1917), com també Adroher (2005-06).

13. Arxiu Comarcal de la Segarra, B-343, f. 2v. Agustí Duran, en publicar l'inventari citat, ja es va adonar que el suposat èxplicit formava part, en realitat, del Tristany (1917a: 315 i 1917b: 129 n.).
} 
no va implicar de cap manera que les versions franceses deixessin de circular: així, a ningú no ha de sorprendre que el bibliòfil Joan I, que el 1362 tenia a les mans una versió catalana del Lancelot, disset anys més tard, el 1379, s'apropiés d'un «bell libre de Lançalot en frances» que el vescomte de Roda, aleshores ambaixador a París, tenia a Perpinyà..$^{14}$

Els textos artúrics esmentats, doncs, van circular contemporàniament pels territoris de parla catalana tant en el francès original com traduïts. Aquest fet pot ajudar a explicar, més enllà de la severitat de l'atzar històric, el nombre limitat de testimonis que ens han arribat de les versions en català, que contrasta amb la relativament elevada quantitat d'esments que es poden documentar d'aquests títols en inventaris i testaments, i amb la productivitat que aquesta tradició evidencia, com s'ha recordat, en l'àmbit de les lletres catalanes. És clar que els escriptors autòctons, en bona part propers a la cort, no sembla que en general tinguessin cap necessitat d'accedir a la matèria de Bretanya mitjançant traduccions. No va ser així, si la cronologia que s'ha apuntat és correcta, ni per a Ramon Llull ni per als cronistes. De ben segur, tampoc per a Guillem de Torroella, que a La faula, anterior a l'octubre de 1374, fins i tot es va permetre de fer parlar diversos personatges en octosíllabs francesos. I no degueren en cap cas necessitar versions en vulgar català ni l'infatigable viatger Joanot Martorell ni l'anònim autor del Curial.

L'estat fragmentari tan lamentable en què es troben els textos catalans del Lancelot i del Tristany, juntament amb les migrades dades externes que en posseïm, ofereixen poques dades sobre el període o el context en què es degueren generar. Fins i tot per a la Questa del sant Graal, que ens ha arribat completa i amb un colofó ben explícit, no és evident si hem d'interpretar que al final del text es fa referència a la data en què el seu traductor va enllestir-ne el trasllat -segons aquesta possibilitat, el 16 de maig de 1380

14. Rubió i Lluch (1908-21: I, cccl). Sobre l'infant Joan i el Lancelot, també ens consta que el 1374 n'havia fet relligar un exemplar, del qual no s'especifica en quina llengua estava escrit (II, CLXXXII).
G. Reixac n'hauria completat la versió-, o bé si s'hi menciona sols el copista que en el dia indicat n'hauria rubricat la còpia de l'Ambrosiana - o, fins i tot, una altra de precedent, de manera que el copista de la conservada s'hauria limitat a copiar el colofó del seu antígraf. En tot cas, diversos dels errors que la versió del còdex milanès conté apunten que no devem trobar-nos pas davant de l'original de la traducció, sinó d'una còpia. No es
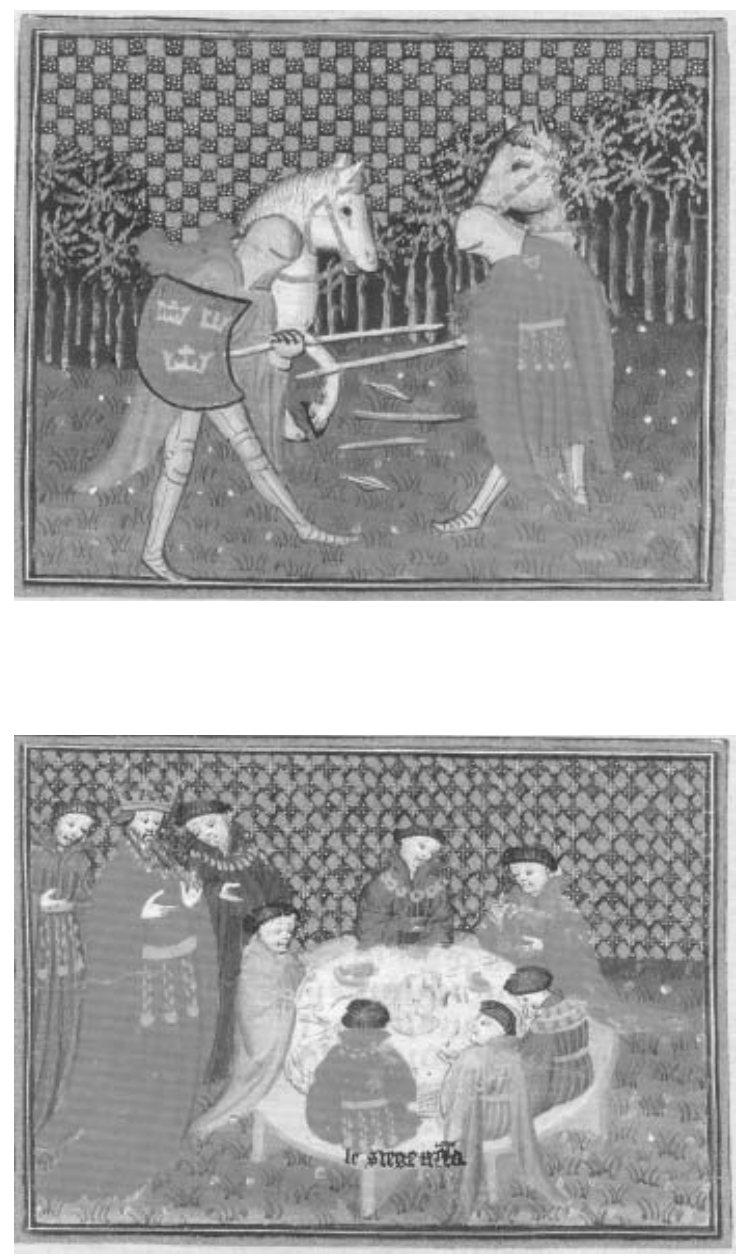

Lancelot lluita amb Tristany i Lancelot acompanya Tristany a la cort del rei Artur (Biblioteca Nacional de Viena, ms. 2.537).

pot descartar, per tant, que el trasllat de la Questa sigui anterior al 1380, com tampoc que el Lancelot fos traduït abans del 1362. Respecte al Tristany, encara que no en tinguem cap dada concreta abans del 1422 i del text que en posseïa Berenguer de Copons, el qual presumiblement només recollia un breu fragment de la història (des de l'inici fins poc després del naixement de l'heroi), tot sembla 
indicar que no és pas al voltant d'aquest any que degué traduir-se, sinó bastant abans. La datació basada en criteris paleogràfics i codicològics dels manuscrits que se n'han conservat ens situa a la segona meitat del XIV. Tots, a més, presenten errors de còpia, cosa que els descarta, també en aquest cas, com a originals de cap traducció.

Tot plegat apunta que va ser durant el llarg regnat de Pere el Cerimoniós, com ja havia assenyalat Antoni Rubió i Lluch, i potser en el del seu fill Joan, que es van dur a terme aquestes traduccions. ${ }^{15}$ És probable, fins i tot, que el trasllat de les obres artúriques que s'han conservat en català -ja sigui de les tres esmentades, o únicament d'alguna d'aquestes-, s'hagi de relacionar amb l'impuls que pare i fill van donar a les traduccions en la llengua del país. No deu ser pas casual que la primera notícia que ens ha arribat del Lancelot català els impliqui tots dos. Ara bé, més enllà del seu possible origen monàrquic i cortesà, cal tenir present que les notícies documentals que en tenim, i els mateixos manuscrits que ens n'han arribat, sobris i ben poc ornamentats, posen de manifest que aquestes obres van circular per sectors socials molt diversos, ja fos en francès o traduïdes, i que en cap cas no van constituir un patrimoni exclusiu dels cercles nobiliaris i més benestants.

\section{La tradició catalana del «Tristany» i els testimonis conservats}

El trasllat català del Tristany no és pròpiament una versió de l'extens Tristan en prose francès. En divergeix pel que fa a la redacció, bastant més del que és habitual en traduccions medievals, com també respecte dels episodis que s'hi relaten o de l'ordre en què s'hi narren. Pel que podem inferir a partir dels fragments conservats, el text català transmetia una versió diferent, i més breu, de les dels textos francesos. Presenta una proximitat molt superior, per contra, amb la traducció castellana i, encara que en un grau més baix, amb part de la tradició italiana, representada

15. Rubió i Lluch (1908-21: II, XXIV), com també Cingolani (1990-91: 83 i 89-90). pel Tristano Riccardiano, la Tavola Ritonda i altres textos menors. Aquests punts de contacte indiquen que les versions catalana, castellana i italiana comparteixen un mateix antecedent, que no s'ha conservat, escrit presumiblement en francès, per bé que també s'ha suggerit que a la península Ibèrica podria haver-hi arribat en versió italiana. Sobre aquest hipotètic antecedent s'ha proposat que devia ser o bé un text que transmetia un estadi redaccional anterior a les versions franceses conservades, o bé una compilació de materials d'origen divers, potser elaborada a Itàlia. ${ }^{16}$

Del Tristany català, se'n coneixien fins ara dos fragments. El primer va ser localitzat per Agustí Duran i Sanpere en un plec de documents de procedència notarial a l'Arxiu Municipal de Cervera. Ell mateix en va publicar el text l'any 1917. Inclou els episodis corresponents a l'alliberament del pare de Tristany, el rei Meliadux, que havia estat encantat i empresonat a la Torre Perillosa, gràcies a la intervenció de Merlí; la localització del protagonista, nounat, després que una donzella I'hagués amagat per por de dos cavallers que volien assassinar-lo; el nou casament del rei, vidu des que la mare del protagonista havia mort poc després del part, i el primer intent de la seva madrastra d'assassinar, amb una copa de vi emmetzinat, el jove Tristany. ${ }^{17}$

L'existència del segon testimoni del Tristany a Andorra la Vella era coneguda des que l'any 1929 Pere Bohigas n'havia parlat en una ressenya dedicada a l'edició d'El Cuento preparada per George Tyler Northup. El text que transmet el manuscrit andorrà, tanmateix, no va ser transcrit i publicat fins quaranta anys més tard per Ramon Aramon (1969). S'hi recullen passatges força més avançats de la història de Tristany que al manuscrit cerverí,

16. Per a la tradició meridional del Tristany i l'hipotètic antecedent comú, vegeu entre altres Sharrer (1979), la introducció de Parodi (1869), Cuesta (1994: 23371), Iragui (1996), Soriano (1999 i 2001: 326-8) i Alvar (2002: 76-8).

17. Els passatges copiats en el manuscrit cerverí es corresponen amb els $\$ \S 20$ i 22 de l'anàlisi de Löseth (1891), i també amb el 21, integrat en la versió catalana dins del 22. El text català d'aquest fragment, que no s'ha conservat en El Cuento de Tristán, acèfal, es correspon amb part dels caps. II-III de l'edició castellana de 1501 (Cuesta 1999: 10a-12b). 


\section{La tradició meridional del Tristany}

L'estudi dels diversos manuscrits i impresos que ens han transmès un text (és a dir la seva 'tradició textual') pot arribar a establir la relació genealògica entre tots aquests 'testimonis'. A través de les tècniques de la crítica textual es pot descobrir, per exemple, si dues versions depenen una de l'altra o si tenen un antecedent comú. En el cas dels testimonis conservats del Tristany en les diferents llengües romàniques, les relacions es podrien resumir amb l'esquema següent:

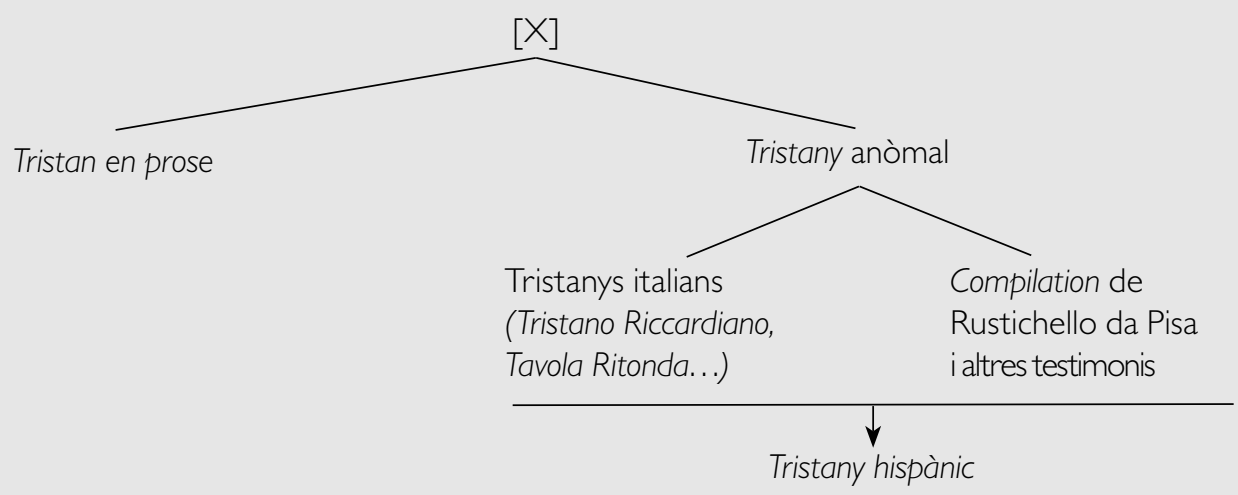

En aquest esquema, $[X]$ fóra l'hipotètic punt de relació, la veritable naturalesa del qual desconeixem, entre el Tristan en prose francès i el Tristany anòmal no conservat que hauria donat lloc a la tradició meridional, que inclouria, si més no, textos francesos, italians, catalans i castellans -no necessàriament en aquest ordre. Els punts de contacte existents entre testimonis d'aquesta tradició posen de manifest el seu parentiu textual, per bé que de moment la crítica no ha trobat evidències que permetin establir amb major concreció aquestes relacions.

En una posició inferior respecte de l'antecedent que hauria generat la tradició meridional (el Tristany anòmal esmentat), caldria situar-hi un segon antecedent de llengua difícil d'identificar a causa de l'estat fragmentari de la tradició, comú a les tradicions catalana i castellana, que explicaria els estrets parallelismes, fins i tot de redacció, que observem en nombrosos passatges.

La traducció castellana es conserva, per una banda, en un còdex castellà trossejat, actualment a la Biblioteca Nacional de Madrid, del qual s'han localitzat una seixantena de fragments d'extensió variable; i, per l'altra, ara en versió completa, en una edició impresa a Valladolid per Juan de Burgos l'any 1501, de la qual depenen les edicions posteriors. No hi ha coincidència entre cap passatge dels fragments castellans manuscrits i els testimonis catalans.
Una segona versió castellana, coneguda amb el títol d'El Cuento de Tristán de Leonís i elaborada probablement a partir d'un model aragonès, ha estat transmesa per un sol manuscrit. Aquest còdex, que forma part del fons de la Biblioteca Vaticana, ha perdut els cinc folis inicials, en què es devien narrar els episodis previs a la partida de Tristany del regne de Leonís. Aquesta segona versió, tot i coincidir amb la primera pel que fa a la narració dels fets, en difereix remarcablement respecte a la redacció i en algunes altres qüestions de detall. El grau de divergència entre les dues versions és prou elevat perquè hagin estat considerades producte de traduccions diferents.

Per al text de l'edició de 1501, vegeu Cuesta (1999); per al còdex manuscrit, Bonilla y Sanmartín (1904), que n'edita el fragment 20.262/19 de la BNM, i Alvar \& Lucía Megías (1999), que en publiquen els cinquanta-nou fragments localitzats a les cobertes d'un volum de dret canònic de final del XV, identificats amb la signatura 22.644 . Aquest còdex hauria servit d'original d'impremta per a l'edició de 1501 (Alvar 2002: 71; Lucía Megías 2005:242-3). Per a la segona versió del Tristán, conservada al ms. 6.428 de la Vaticana, vegeu Tyler Northup (1928). Sobre la divergència de les versions, vegeu Tyler Northup (1928: 24-76), com també Cuesta(1999: XVI-XVII). 


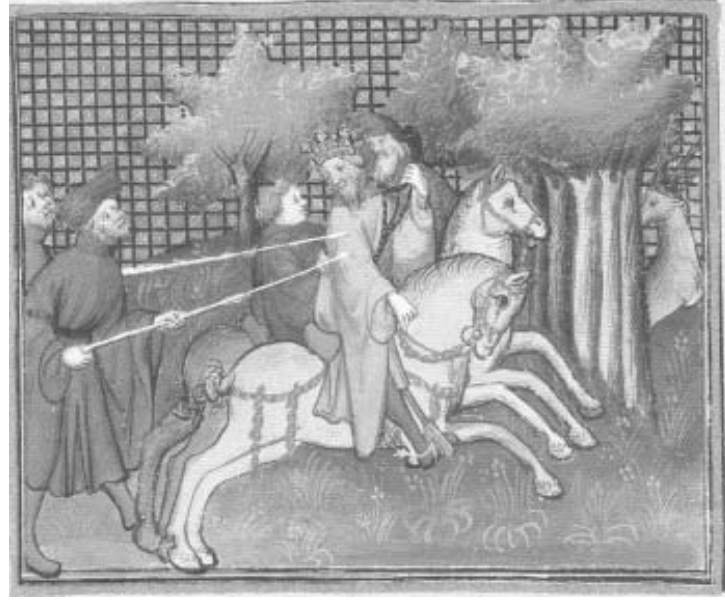

El rei Meliadux amb el seu fill Tristany de cacera. El rei és assassinat i Governal aconsegueix salvar el petit Tristany (Biblioteca Nacional de Viena, ms. 2537).

atès que s'hi narra la seva relació amb Isolda de les Blanques Mans a partir de la nit de noces, que I'heroi decideix no consumar. També hi trobem la difusió de la nova del seu matrimoni, que porta a Cornualla el cavaller Lembrogesi, marit de la Dona del Llac de l'Espina i derrotat per Tristany en episodis anteriors. En assabentar-se'n, la reina Isolda la Blonda envia la seva donzella Brangina, amb una carta de retret, per confirmar o desmentir la veritat dels fets. Una vegada a la Petita Bretanya, ella, Tristany i el germà d'Isolda de les Blanques Mans, Gedís -Kahedin en el text francès-, parteixen cap a Cornualla, per bé que s'aturen a la Gasta Forest, en la qual els dos cavallers opten per endinsar-se amb l'objectiu de cercar-hi aventures. El fragment queda tallat a mig combat entre Tristany i Lamorat de Gallles, després que el darrer hagi vençut Gedís i també un primer assalt a Tristany -no per mancança seva, sinó per culpa del seu cavall. ${ }^{8}$

El 18 de juliol de 2008 va entrar a formar part del fons de la Biblioteca de Catalunya un nou testimoni del Tristany català, igualment fragmentari. Es tracta de dos bifolis d'un mateix còdex, donats a la Biblioteca per la professora Eulàlia Duran, filla

18. El text del fragment del Tristany contingut en aquest còdex correspon aproximadament als $\S \S 56-57,60$, 58,63 i 71 a de l'anàlisi de Löseth (1891), $\mathrm{i}$ als caps. XL-XLII de la versió espanyola impresa a Valladolid el 1501 (Cuesta 1999: 89b-96a) i als §§ Cl-CXII de Tyler Northup (1928: 187-201). de l'historiador que va publicar el text del primer manuscrit trobat. El nou fragment va ser localitzat entre els papers de l'investigador, de manera que podria ser que provingués del mateix arxiu que el primer testimoni, tot i que no se'n té la certesa. La dificultat de lectura d'extensos passatges del manuscrit, molt afectat per la humitat, devien haver fet desistir l'arxiver cerverí de transcriure el text complet i de donar-lo a conèixer, atès que entre els seus papers relatius al Tristany també hi ha un esborrany incomplet de la transcripció. Contràriament al que es podria creure, tenint en compte que la troballa podria haver-se dut a terme al fons on hi havia el primer fragment identificat, el nou testimoni tristanià no forma part del mateix còdex que el primer. Les mides i altres característiques dels manuscrits, del tot divergents, i igualment la manca d'identitat pel que fa a les mans que els elaboraren, posen de manifest que es tracta de folis procedents de còdexs independents. A aquestes raons de tipus material encara cal afegir que, com veurem més avall, els textos transmesos pels dos testimonis coincideixen en un mateix passatge, malgrat que breu, corresponent al final del text copiat al ms. B-343 de l'Arxiu de Cervera i a l'inici del de la Biblioteca de Catalunya.

\section{El contingut del nou testimoni}

En el primer dels dos fragments que formen els bifolis de la Biblioteca de Catalunya (A, ff. e-h) es recull el primer intent de la madrastra de Tristany d'assassinar-lo, que trobàvem igualment al fragment conservat a Cervera; hi ha igualment el segon, que acaba amb la mort accidental del seu fill, germanastre de Tristany. A continuació el rei és assassinat, en el curs d'una cacera, per un grup de cavallers. El relat recull llavors un tercer intent d'enverinar Tristany de la perseverant madrastra, ara ja vídua, en un convit. Després del banquet, veient la mala intenció de la reina, el preceptor de Tristany, Governal, decideix endur-se'l a la cort del rei Farmon de Galles. ${ }^{19}$

19. Per a aquest tercer intent, també recollit en el Tristán de 1501 i el Tristano Riccardiano, però no en tex- 
A la cort gallesa es produeix la visita de Lamarolt d'Irlanda -el Morhout de la versió francesa-, al qual un foll adverteix del perill que Tristany suposarà per a ell, sense que en faci cabal. Més endavant, Belisén, filla de Farmon, prova de seduir Tristany; davant la resistència del cavaller, l'acusa d'intent d'agressió i aconsegueix que se'l condemni a mort. Tristany és alliberat quan el rei, per provar-la, posa Belisén en la disjuntiva de triar entre salvar Tristany o el seu propi cosí, també condemnat a mort, i ella opta, no sense haver-hi donat unes quantes voltes, per l'innocent. De nou en llibertat, l'heroi i Governal deixen la cort; abans de marxar, Tristany revela a Farmon la seva identitat, fins llavors amagada. A continuació, per despit, Belisén se suïcida, per bé que abans escriu una carta a Tristany; l'hi fa lliurar juntament amb l'espasa amb què s'ha suïcidat, un cavall i un gosset. El text del primer bifoli queda tallat quan el missatger de Belisén inicia el diàleg amb Tristany i Governal. ${ }^{20}$

Podem, molt sumàriament, assajar de recuperar el contingut dels quatre folis següents, perduts (els hipotèticament signats $i-q$ ), a partir de testimonis castellans i italians. ${ }^{21}$ S'hi devien narrar l'arribada a Cornualla de Tristany; la lluita amb l'irlandès Morhout quan aquest exigeix a Marc el tribut degut, de la qual, malgrat que vencedor, Tristany surt malferit per una fletxa emmetzinada tirada a traïció; l'anada a Irlanda a la recerca d'una cura, que Isolda durà a terme amb èxit; l'inici de la rivalitat amb Palomedes, a qui venç en el torneig d'Escòcia, per l'amor de

tos francesos ni en d'altres d'italians, vegeu Soriano (2001). El text d'El Cuento s'inicia just amb la decisió de Governal d'allunyar-se de Leonís, en constatar que la «[ma]drastra vos trae mala voluntad» (Tyler Northup 1928: 79).

20. El text del bifoli A coincideix amb part dels $\$ \S 22-27$ de l'anàlisi de Löseth (1891), i també amb els paràgrafs I-Vı de Tyler Northup (1928: 79.1-83.27), i els caps. IV-V de l'edició castellana de 1501 (Cuesta 1999: 12b19b).

21. Parteixo sobretot de Tyler Northup, $\S$ VI-XXX (1928: 83-100); com veurem, aquesta versió presenta afinitats destacades amb el manuscrit de la Biblioteca de Catalunya. Tinc també en compte l'edició de 1501, caps. V-XVI (Cuesta 1999: 19b-38a), i Parodi, § XIIIXLVII (1869: 78-118). la princesa; el descobriment, per part de la reina, que Tristany havia estat el responsable de la mort del Morhout i la intercessió cortesa i justa del rei Languís - Hanguin en el text francès-, que salva el protagonista; el retorn a Tintagel, la celebració d'un torneig en honor de Tristany i el combat singular entre ell i el rei Marc a causa de l'enveja que l'oncle sent pel nebot, objecte dels requeriments amorosos de la Dona de l'Espina; la nit d'amor entre Tristany i la dama esmentada, bruscament interrompuda per l'arribada del marit d'aquesta - personatge que ja hem citat en parlar del manuscrit andorrà-, el qual descobreix la infidelitat de la seva esposa en localitzar taques de sang als llençols, procedents de les ferides de Tristany; la persecució de Tristany pel cavaller i la derrota d'aquest darrer; el pas pel territori de dos cavallers del rei Artús, als quals Marc envia el seu nebot Guodino a informar-se de noves, i la reacció violenta dels cavallers a causa de l'actitud poc cortesa de Guodino; i, finalment, l'arribada a la cort de Marc del cavaller Brunor, nebot de Lancelot, que escull la Dona de l'Espina per la seva bellesa i, davant la manca d'oposició dels cavallers presents, se l'emporta.

Abans de passar a comentar el contingut del segon fragment de la Biblioteca de Catalunya, no és sobrer remarcar un aspecte en què divergeixen les versions de la història que he tingut en compte per salvar el buit que es produeix en aquest manuscrit entre els dos bifolis. En el còdex de la Vaticana es narra la derrota de Guodino a mans dels dos cavallers estrangers just abans de la irrupció de Brunor a la cort. En canvi, en l'edició castellana de 1501 i en el Tristano Riccardiano aquest episodi, incloses les causes que el motiven, és narrat més endavant, una vegada Brunor s'ha endut la Dona de l'Espina de la cort de Marc. Atès que en el testimoni de la Biblioteca de Catalunya, que s'inicia amb la partida de Brunor de la cort, no s'especifiquen les causes de la topada de Guodino quan Tristany se'l troba malferit, com veurem tot seguit, és versemblant que aquests aclariments es donessin en els folis perduts, és a dir, en el mateix lloc que en El Cuento de Milà. ${ }^{22}$

22. Vegeu els passatges esmentats en Tyler Northup, $\S$ XXIX (1928: 100); Cuesta Torre, cap. XVI (1999: 389); Parodi, § XLVII (1869: 119-20). 


\section{Manuscrits del «Tristany» català}

\section{El Tristany de Cervera}

Aquest testimoni, datable de final del segle XIV, és constituiit per quatre folis de paper de dimensions reduïdes. Es tracta del ms. B-343 de l'Arxiu Comarcal de la Segarra, on es conserven els fons de l'ajuntament de Cervera; val a dir, però, que des de fa alguns anys se'n desconeix la localització. D'acord amb les dades que en dóna Agustí Duran, els folis fan $225 \times 155$ mm. Tal com es pot apreciar a les reproduccions que en publica ell mateix, especialment el terç superior del marge oposat al llom dels quatre folis es troba en força mal estat, amb alguns estrips que, tot i l'amplitud dels marges de la caixa, han afectat en algun cas el text. L'escriptura és a ratlla tirada, amb 22 línies per pàgina, i s'hi ha deixat en blanc l'espai per a les caplletres. Al recto dels ff. 1 , 3 i 4 són visibles els marges de la caixa. Per a aquest testimoni, vegeu Duran (1917a: 284) i Ros (2001: esp. 57-9).

\section{El Tristany d'Andorra}

Es tracta de quatre folis inclosos en un volum factici, el ms. 1 de l'Arxiu de les Set Claus, conegut amb el nom de Còdex miscellani; actualment forma part del fons de l'Arxiu Històric Nacional d'Andorra. El text tristanià que es va copiar en aquests folis, corresponents als ff. $32^{r}-35^{\vee}$ del volum, és consecutiu i no presenta llacunes derivades de la pèrdua de folis intermedis. El paper és de mida superior a l'anterior, atès que fa 290 $\times 210 \mathrm{~mm}$. El text és escrit a doble columna, amb 33 línies cadascuna, amb lletra cursiva de la segona meitat del segle XIV. S'hi van elaborar caplletres de color vermell, i hi ha algunes capitals que presenten així mateix una certa ornamentació, també en vermell. Esporàdicament s'hi aprecien restes de les ratlles horitzontals per marcar els marges de les columnes. Per a una descripció completa, Santanach (2003: esp. 434-5); vegeu també Aramon (1969: 324-5), Ros (2001: 59-63), Santanach (2002 i 2002) i Lucía Megías (2005: 251-3).

\section{El Tristany de la Biblioteca de Catalunya}

El nou testimoni, al qual s'ha atribuït la signatura 8.999/1, és compost per quatre folis de paper, de $300 / 295 \times 226 / 222 \mathrm{~mm}$, els quals constitueixen dos bifolis de característiques idèntiques. Al foli davan- ter de tots dos fulls hi ha una mateixa filigrana que representa un ganivet de fulla ampla, molt proper a Valls (1970), 1506, per bé que el mànec del tallant del manuscrit tristanià és una mica més llarg; Valls el documenta l'any 1380.

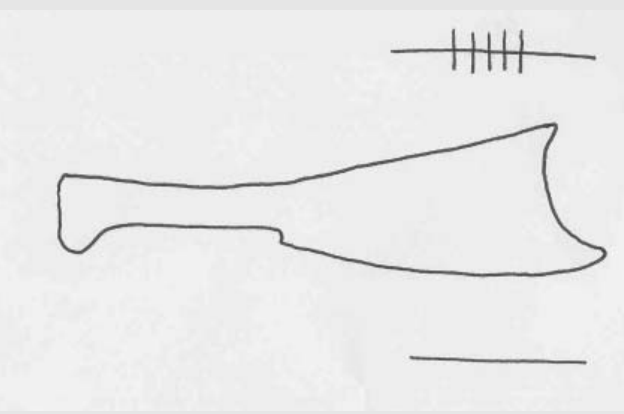

No sembla que aquests bifolis hagin format mai part d'un volum relligat, perquè no presenten marques al llom d'haver estat cosits ni els seus marges han estat tallats per cap relligador.

Els bifolis recullen dos fragments diferents, no consecutius, del Tristany; distingeixo els passatges que s'hi han copiat amb les lletres A i B. El text de cadascun és seguit i sense salts interns, cosa que lliga amb les signatures de les quatre pàgines, així mateix consecutives: l'ordre en què s'han de llegir ha estat assenyalat, al marge superior esquerre de cada pàgina, amb les lletres e, $f, g, h$ (les del primer bifoli, A) i r, s, t, u (les del segon, B), per la mateixa mà que ha copiat el text. A partir d'aquesta constatació es pot plantejar que cada bifoli constituïa un plec independent, de manera que conservaríem els plecs segon i cinquè del conjunt (és a dir, davant hi hauria hagut d'haver un sol plec, a-d, i dos més entremig, les pàgines dels quals s'haurien hagut de correspondre amb les lletres i, k, l, m, i n, o, p, q). També pot ser, és clar, que es tracti dels dos bifolis centrals dels dos plecs inicials del volum projectat, que haurien estat formats per sis folis cadascun $\left(3^{+} 3\right)$, de manera que el primer quadern estaria constituït per les pàgines a-m, i el segon s'iniciaria a la pàgina $n$ i s'acabaria dos folis més enllà d'u -o sigui, la darrera que n'hem conservat. En aquesta darrera suposició, l'esquema de distribució dels folis pertanyents als dos hipotètics quaderns inicials del Tristany fóra el següent (indico en negreta els folis conservats): 


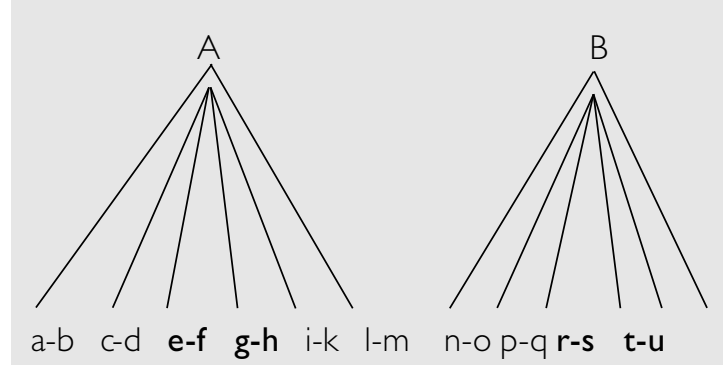

Els dos fragments, tot i l'amplada de la caixa d'escriptura $(290 / 285 \times 215 / 210 \mathrm{~mm})$, són redactats a ratlla tirada, amb lletra cursiva de cos reduï, datable a començament del segle $x \mathrm{~V}$, i presenten de 43 a 55 línies per pàgina. A l'hora d'escriure, pràcticament no s'han deixat marges de respecte (la seva amplada tot just va dels 4 als $14 \mathrm{~mm}$ ), i això que, com s'ha dit, els folis no han estat tallats per la cisalla. Les dimensions reduïdes de la lletra i dels marges, juntament amb la manca de rastres que haguessin estat cosits, fan pensar que ja en copiar-los no es pretenia que

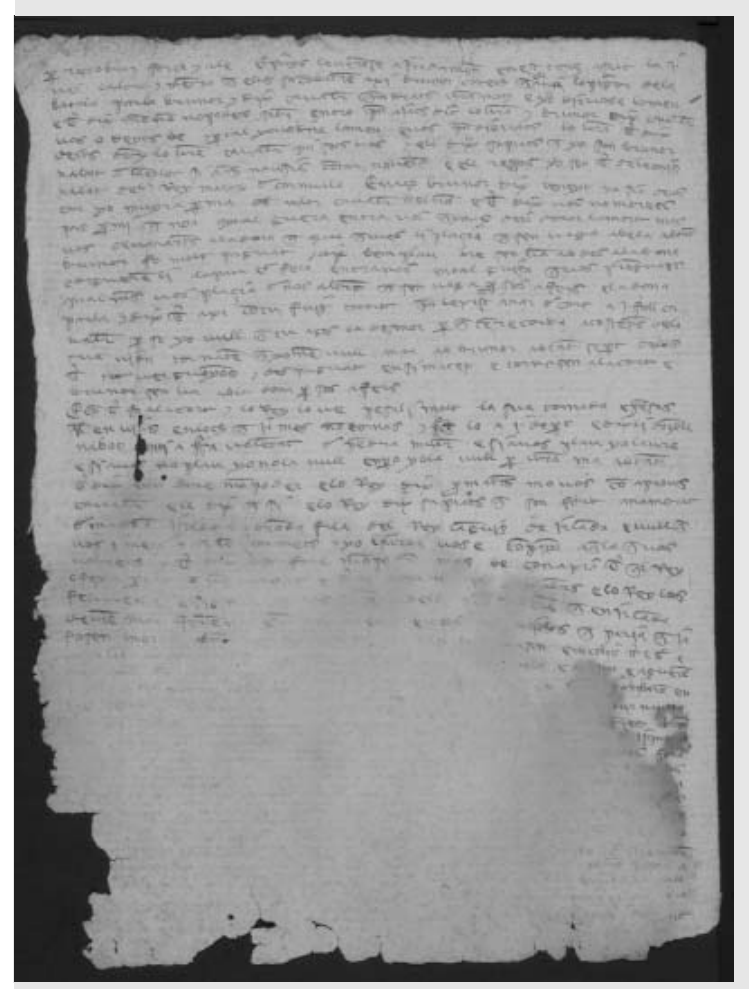

BdC, 8.999/1, f. f. S'hi relata l'assassinat del rei Meliadux, el tercer intent d'emmetzinament de Tristany per la seva madrastra, l'arribada a la cort de Galles i la visita de Lamarolt d'Irlanda al rei Farmon. (Foto: Jordi Vidal) acabessin constituint un volum relligat. Podria ser, per tant, que l'objectiu de l'elaboració d'aquest testimoni estigués únicament destinada a proporcionar una còpia en brut prèvia a la confecció d'un còdex amb tots els requisits formals que fessin el fet. Tampoc no es pot descartar que es tracti d'una còpia destinada a l'ús propi.

La no inclusió dels folis conservats en un còdex ha d'haver estat determinant en el deteriorament causat pel pas del temps, i també en la dispersió dels folis que devien conformar el conjunt de la còpia. Els quatre folis conservats han estat afectats per greus humitats, com evidencien els estralls causats en el terç inferior de la seva superfície, que pràcticament n'ha fet desaparèixer la tinta. Aquesta degradació ha comportat que extensos passatges del text siguin del tot illegibles sense el recurs dels rajos ultraviolats. Els marges dels folis, d'altra banda, estan també en força mal estat, amb diversos estrips que, en algun cas, han afectat el text copiat.

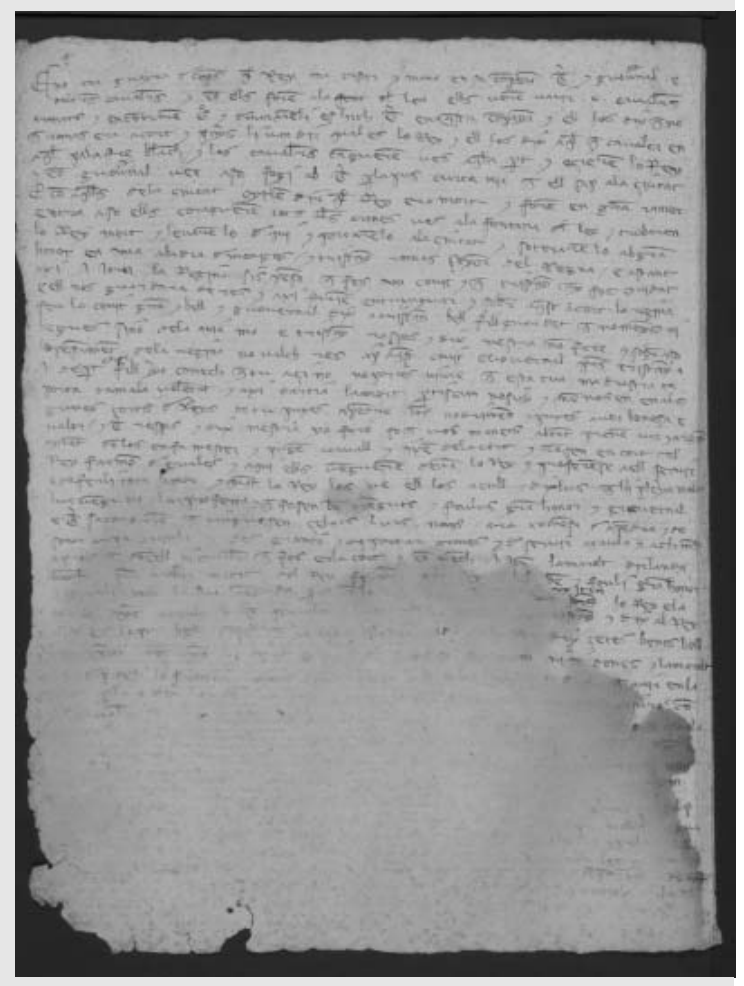

BdC, 8.999/1, f. s. Combat entre Tristany i Brunor; decisió de la Dona de l'Espina de quedar-se amb Brunor; encàrrec de Marc a Tristany de negociar la mà d'Isolda; aturada de la nau que el duu al regne de Longres. (Foto: Jordi Vidal). 


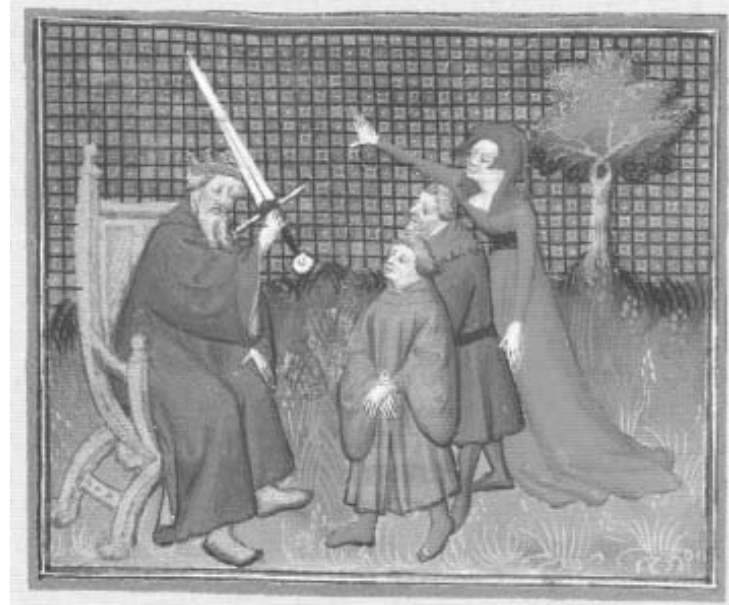

Belisén acusa Tristany d'haver-la volgut forçar per despit. Tristany compareix davant el rei, amb les mans lligades, acompanyat de Governal (Biblioteca Nacional de Viena, ms. 2537).

s'inicia amb la decisió del marit de la dama raptada de perseguir-los, tot sol perquè no hi ha cap cavaller de la cort que s'ofereixi a acompanyar-lo; en atrapar-los, és vençut per Brunor. La història torna a la cort, on una donzella acusa Tristany de fals cavaller -segons altres versions, aquesta donzella hauria estat enviada per la Dama de l'Espina. Després que hagi marxat, l'heroi decideix seguir-la per demanar-li explicacions. En el trajecte troba el seu cosí Guodino malferit, i s'ofereix per venjar-lo tot i la queixa de Governal per la seva excessiva predisposició a assumir qualsevol combat. Quan localitza els dos cavallers que han atacat el seu cosí, els derrota l'un darrere l'altre. Guodino torna a la cort i, malgrat la interdicció de Tristany, explica al seu oncle Marc qui l'ha venjat. Tristany, per la seva banda, continua la persecució de Brunor i veu que entra en un castell per passar-hi la nit; ell i Governal s'hostatgen a casa d'una vídua, el fill de la qual el reconeix com el vencedor del torneig del rei d'Escòcia, encara que Tristany nega haver-hi pres part. L'endemà es produeix el combat amb Brunor i, en una aturada, s'identifiquen; llavors Tristany decideix no continuar lluitant i oferir a la dama que esculli amb quin dels dos se'n vol anar. En aquest punt, el manuscrit de la Biblioteca de Catalunya coincideix de nou amb la versió d'El Cuento; en la versió castellana impresa o en el Tristano Riccardiano, per contra, és Brunor qui, veient que té les de per- dre, fa aquesta proposta a Tristany. ${ }^{23}$ En qualsevol cas, el resultat és el mateix, ja que la dama, ofesa amb Tristany perquè no l'havia defensada a la cort, opta per quedar-se amb Brunor.

De tornada a la cort, Marc li encarrega la perillosa missió d'anar a demanar la mà d'Isolda la Blonda a Languís d'Irlanda; se n'hi va amb quaranta cavallers que el rei li ha concedit, tots convençuts - llevat de Tristany- que no tornaran a Cornualla. En arribar al regne de Longres, Tristany fa plantar dos pavellons amb escuts a fora per tal que el desafiin els cavallers que passin per allà; en derrota dos, davant dels quals simplement s'identifica com un cavaller de Cornualla, cosa que omple de malenconia els vençuts. A continuació es produeix la trobada amb el rei Languís d'Irlanda, que es dirigia a Camelot per defensar-se de l'acusació, que Brunor li imputa, d'haver assassinat un cavaller malalt que havia acollit a la cort; el rei demana a Tristany que ocupi el seu lloc en la batalla amb Brunor, i aquest accepta a canvi d'un do que no s'especifica, però que més endavant, ja fora dels passatges que ens han arribat en català, es concreta en la mà de la seva filla Isolda per al seu oncle Marc.

Poc després, Tristany troba una donzella que porta a Camelot un escut mig partit amb la figura d'un cavaller i una dama (encara que no s'indica

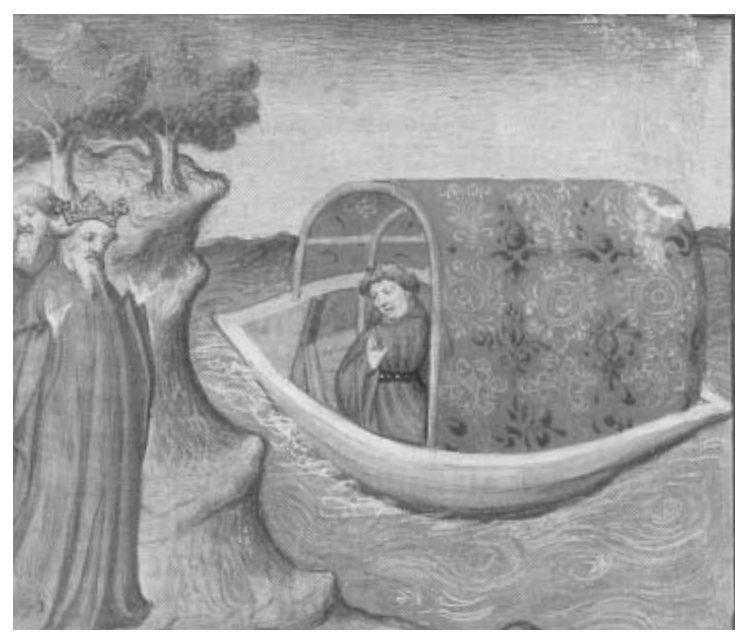

Tristany es posa al servei del seu oncle, davant el rei Marc de Cornualles, després de matar el gegant Morhout (Biblioteca Nacional de Viena, ms. 2.537).

23. Vegeu Tyler Northup, $\S X X X I I I$ (1928: 103), Cuesta Torre, cap. XVII (1999: 41), i Parodi $§ L$ (1869: 126). 
al fragment conservat, es tracta d'una missatgera de la Dama del Llac, que envia l'escut a la reina Ginebra per fer-li saber que coneix els seus amors amb Lancelot). Quan se separen, un cavaIler ataca la donzella i li pren l'escut; ella demana ajuda a Tristany, que s'enfronta al cavaller descortès i el derrota; una vegada a terra i quan Tristany és a punt de tallar-li el cap, es nega a identificar-se fins que l'heroi li garanteix que el deixarà viure; quan li diu que és Breus Sens Pietat, Tristany lamenta haver-lo assegurat, però li ordena que es presenti a Galvany, del qual sap que té deutes pendents amb Breus. La donzella, llavors, explica a Tristany que a Camelot hi ha el rei de Cent Cavallers i el d'Escòcia, i quatre altres monarques que s'han constituït en tribunal per donar sentència en la disputa entre Brunor i Languís; Tristany en dóna compte al rei d'Irlanda. L'endemà al matí cavalquen fins a Camelot, Languís amb robes més riques que Tristany, tot i que es remarca que aquest en posseïa de tan valuoses com les del rei. Allà, Languís presenta Tristany com el seu campió i Brunor li dóna el guant com a gatge. Arribat el dia del combat, Bordo i Leonell, cosins de Brunor, el pressionen perquè lluiti bé i faci honor al seu llinatge; durant el segon assalt, però, en què es comença a fer evident que el seu cosí es mostra inferior a Tristany, marxen sense esperar el final. Brunor, conscient que el seu rival és més bon cavaller, li demana que s'identifiqui. El fragment queda tallat quan Tristany accedeix a donar-se a conèixer, cosa que no fa, però, fins que Brunor ha pronunciat abans el seu nom (hem d'entendre que l'exigència de Tristany és més cavalleresca que informativa, ja que en principi sabia perfectament qui era el seu rival). ${ }^{24}$

\section{Entre còpies i trasllats}

El fet que pràcticament no hi hagi coincidències entre els passatges de l'obra conservats als fragments catalans dificulta en gran manera - de fet, impossibilita - la constatació de cap mena de parentesc textual entre els tres manuscrits. Només dos dels testimonis reporten, com s'ha indicat, un mateix passatge, molt breu, corresponent a un dels intents d'enverinament de què és víctima el jove Tristany. El

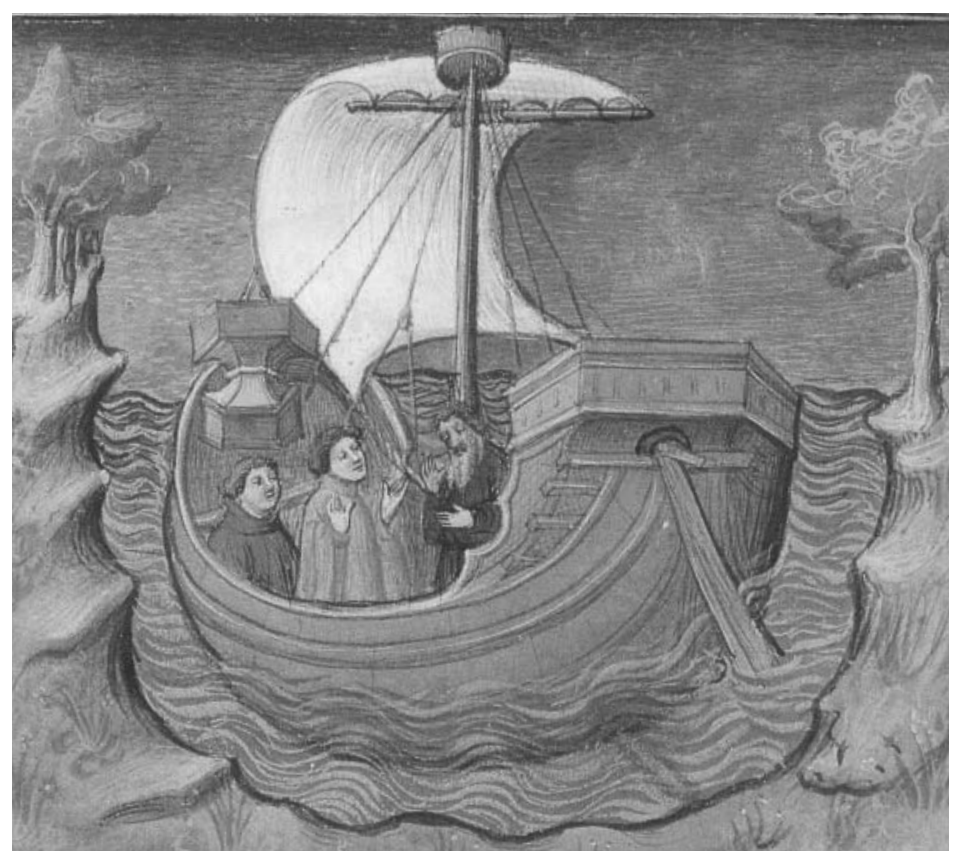
fragment en qüestió, que es troba al final del manuscrit de l'Arxiu de Cervera i a l'inici del de la Biblioteca de Catalunya, és massa curt per extreure'n conclusions amb prou fonament. Em limito a apuntar amb tota cautela que, malgrat que s'hi observin algunes lliçons divergents, en línies generals semblen procedir d'un mateix arquetip. Més enllà d'aquesta hipotètica consideració dels dos manuscrits com a còpies d'un mateix text, no és possible saber, per la manca remarcada de punts de contacte, si el testimoni català d'Andorra deriva igualment del mateix arquetip que els altres dos. Aquesta situació, la impossibilitat de constatar la dependència dels tres testimonis d'un únic arquetip, en el fons

\footnotetext{
24. El text del bifoli $B$ coincideix aproximadament amb els $\S 34-38$ de Löseth (1891), els $\S$ XXX-XXXVIII de Tyler Northup (1928: 100.30-109.10) i els caps. XVI-XIX de l'imprès (Cuesta 1999: 38a-45b).
} 
implica la impossibilitat de saber si cal considerar-los o no còpies d'una mateixa traducció. En aquest sentit, pot ser orientador tenir en compte les altres tradicions lingüístiques de la narració, i especialment les traduccions castellana i italiana.

Des que Agustí Duran i Sanpere va donar a conèixer el primer fragment tristanià localitzat a Cervera, i va observar que els passatges que transmetia «es corresponen fidelment en tot el fragment» (1917a: 285) amb el text de l'imprès castellà de 1501, s'ha tendit a agrupar la versió catalana amb la castellana de l'imprès i del còdex de la Biblioteca Nacional de Madrid, de manera que aquest conjunt de testimonis formaria un grup independent respecte de l'altra versió castellana, la d'El Cuento de Tristán de Leonís de la Biblioteca Vaticana. Ara bé, El Cuento és acèfal i no transmet el passatge copiat al manuscrit cerverí; és a dir, no és possible contrastar fins a quin punt el text català divergeix d'aquesta traducció castellana. Fos com fos, la localització del fragment català d'Andorra semblava confirmar aquesta agrupació, ja que en línies generals presenta una semblança més acusada amb el text imprès que no amb el còdex vaticà, llevat d'algun passatge puntual, com la carta que Isolda tramet a Tristany, que comentaré tot seguit. 25

Aquesta premissa, però, potser s'hauria de deixar en suspens a la llum del text copiat al testimoni de la Biblioteca de Catalunya, ja que presenta afinitats més accentuades amb la versió d'El Cuento que amb la dels impresos del XVI, constatable tant pel que fa a la literalitat de determinats passatges com en altres detalls relatius a l'ordre dels episodis narrats o en el desenvolupament de l'acció. Més amunt n'he indicat alguns exemples: ni el text català ni El Cuento expliquen les causes que han provocat que dos cavallers agredeixin

25. El parallelisme epistolar no impedeix que M. Luzdivina Cuesta, en valorar les relacions entre les versions hispàniques del Tristany, situii coherentment amb la resta d'indicis els fragments catalans de què té notícia sota un subarquetip que inclou igualment el grup castellà esmentat, però no el manuscrit de la Vaticana (1994: 259-68). Menys evident és, en canvi, l'arbre que es proposa en Alvar (2002: 69-72). Per al fragment andorrà i el text de 1501, vegeu també Soriano (1999: 419).

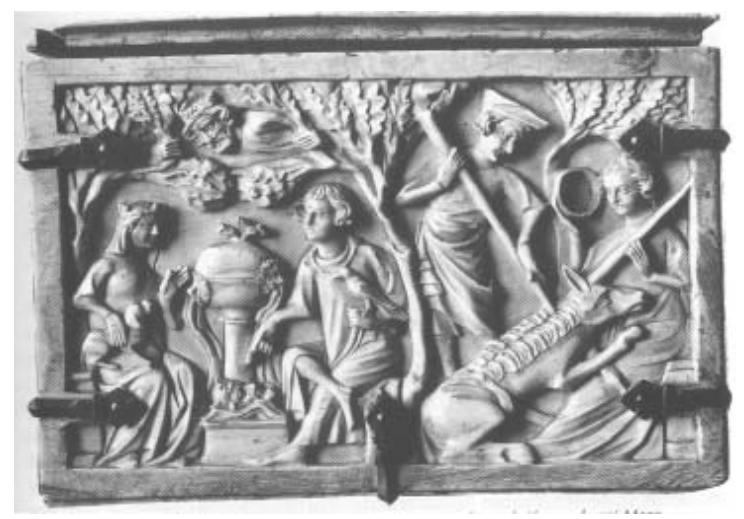

Tristany i Isolda espiats pel rei Marc. A la dreta l'Unicorn, símbol de luxúria (Cofre d'ivori del segle xIv (Metropolitan Museum of Art, Nova York).

Guodino en el mateix lloc que ho fa el text imprès de 1501, aspecte en el qual aquest darrer coincideix amb el Tristano Riccardiano. Els textos mencionats s'agrupen de la mateixa manera una mica més endavant, a l'hora d'atribuir la proposta d'aturar el combat amb Brunor a un o altre contendent, que en el text català i en El Cuento sorgeix de Tristany, mentre que en les altres dues versions es presenta com un estratagema del seu rival per evitar ser derrotat.

Aquesta primera aproximació és encara provisional, a l'espera d'una anàlisi més detallada dels diversos materials, per bé que ens permet plantejar la versemblant proximitat genètica d'El Cuento amb el testimoni de la Biblioteca de Catalunya i, potser, si efectivament depèn del mateix arquetip que aquest darrer, com el breu fragment compartit sembla indicar, el manuscrit de Cervera. Aquesta possibilitat no s'hauria de contradir amb la proximitat manifesta del testimoni cerverí amb el text de 1501: no són pas pocs els llocs en què les dues traduccions castellanes reporten versions properes d'uns mateixos passatges, i no fóra gens sorprenent que els folis perduts al començament del manuscrit d'El Cuento relatessin els episodis inicials en uns termes poc allunyats dels del text imprès.

Aleshores el que caldria plantejar és quina deu ser la relació d'aquests dos testimonis catalans amb el manuscrit conservat a l'Arxiu Històric Nacional d'Andorra. Com s'ha remarcat, els punts de contacte, ben evidents pel que fa a la redacció, entre aquest i les edicions castellanes 
l'allunyen de la versió d'El Cuento malgrat que hi tingui alguns punts de contacte, segurament no tant atribuïbles a cap dels dos textos manuscrits com a innovacions en el text imprès. Així, la carta d'Isolda a Tristany, en el contingut de la qual coincideixen en molts aspectes el fragment d'Andorra i El Cuento, contra la versió que en podem llegir en l'edició de 1501, és una peça retòrica fàcilment reescrivible i amplificable d'acord amb la moda de la ficció sentimental, influència que ha estat remarcada repetidament en el text castellà imprès. ${ }^{26}$ També es podria esmentar l'afinitat que hi ha entre el fragment andorrà i El Cuento en un aspecte tangencial del primer encontre de Tristany amb Lamorat de Galles, després que aquest hagi vençut Gedís. Segons les dues versions esmentades, Tristany és superat per Lamorat a causa del seu cavall, incapaç de suportar l'empenta del seu rival, mentre que en el text de 1501 és el cavall del contrincant el que perd peu. La consulta del Tristano Riccardiano, en què el cavall vençut és efectivament el de Tristany, ${ }^{27}$ posa de manifest que altra vegada deu tractar-se d'una innovació del text de 1501, o d'un antecedent seu, generada potser per no haver d'atribuir una derrota a l'heroi, malgrat que no es degui a les seves habilitats guerreres sinó a la muntura.

Tot i les limitacions relatives als punts de comparació entre les versions catalana i castellana, i a la seva mateixa condició de traduccions, que implica un grau d'intervenció superior al que és propi d'un copista, els llocs indicats permeten intuir una agrupació dels testimonis hispànics en dos conjunts diferents dels que fins ara s'havia considerat. En efecte, mentre que el manuscrit de la Biblioteca de Catalunya -i el seu possible germà de Cervera- mostra una major afinitat amb el text castellà d'El Cuento, el conservat a Andorra sembla més proper als impresos del XVı i al còdex fragmentari que en transmet la mateixa traducció. En conseqüència, si els testimonis castellans són producte de dues traduccions independents,

26. Per a les versions de la carta, Cuesta, cap. XLI (1999: 91-2); Tyler Northup, $§ \mathrm{cv}$ (1928: 191-2), i Parodi, $\S$ CXLIII (1869: 278-9). Vegeu també els comentaris de M.L. Cuesta en la introducció de la seva edició (1999: XXIII-XXVII), on es recull la bibliografia pertinent. 27. Vegeu Parodi, § CLV-CLVI (1869: 295-6). per bé que l'original en tots dos casos sigui un mateix Tristany anòmal -o versions d'aquest Tristany anòmal-, també caldria plantejar fins a quin punt els testimonis catalans conservats que es relacionen amb les traduccions castellanes podrien ser així mateix còpies de dos trasllats diferents. En qualsevol cas, sembla raonable mantenir la hipòtesi d'un únic antecedent hispànic, l'existència del qual és versemblantment confirmada per les afinitats entre els dos grups, que els allunyen dels textos francesos i, de vegades també, dels italians. Alhora, sembla igualment versemblant que haguem de parlar de dues branques diferenciables pel grau d'innovació que mostraria el subarquetip d'una d'elles -la del testimoni de la

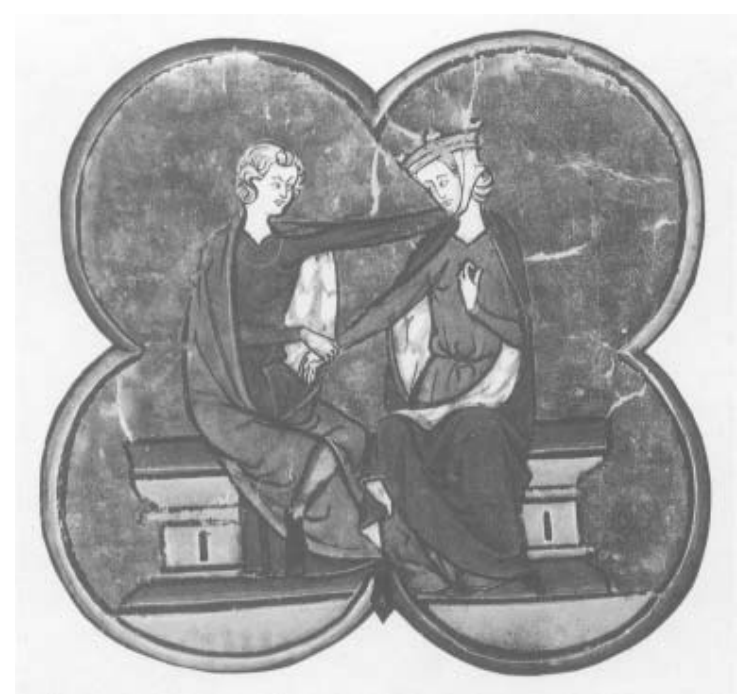

Tristany i Isolda. Miniatura d'un Tristany en prosa (Biblioteca Nacional de França, ms. fr. 2.186).

Biblioteca de Catalunya i El Cuento-, contra una altra branca amb solucions més conservadores, que mantindria un nombre més elevat de coincidències amb la tradició italiana representada pel Tristano Riccardiano. Podem representar les relacions esmentades, que de moment encara cal considerar provisionals, amb l'esquema següent:

En el nostre esquema (veure plana següent), Y representa l'antecedent comú a la tradició hispànica del Tristany (amb l'excepció d'un fragment gallegoportuguès, fins ara no esmentat perquè és molt proper a les versions franceses canòniques del Tristan en prose). Tant $Y$ com a i poden 


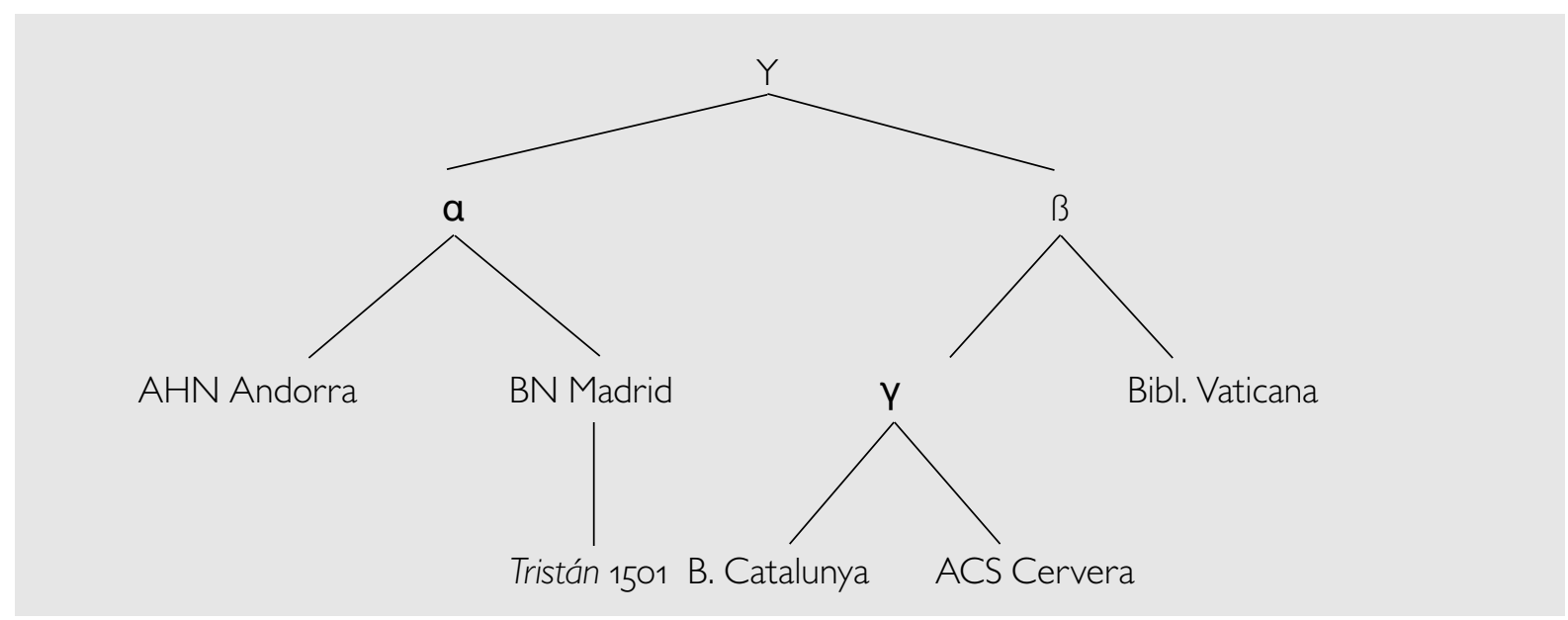

constituir originals de traduccions a una de les dues llengües peninsulars implicades o, fins i tot, sobretot en el cas de $\beta$, podria tractar-se de l'original de la versió aragonesa. Malgrat que és probable, com han plantejat diversos estudiosos des que Pere Bohigas ho va suggerir, que la traducció catalana es trobi a la base de la resta de traduccions peninsulars textualment emparentades, les evidències de què disposem no són per ara concloents. Finalment, y fóra l'hipotètic antecedent català compartit pels fragments de la Biblioteca de Catalunya i de l'Arxiu Comarcal de la Segarra; no hem de descartar, però, que aquest darrer testimoni s'hagi de situar sota $\mathbf{a}$.

No cal insistir en el fet que partint de testimonis tan mutilats es fa difícil anar més enllà de l'àmbit de les hipòtesis, i més tenint en compte que encara disposem d'un coneixement poc aprofundit sobre les relacions de dependència entre les versions castellanes i catalanes. I, no cal dir, amb els pocs indicis que es poden esgrimir respecte a les versions de l'obra que van donar lloc a les tradicions meridional i hispànica.

\section{Bibliografia citada}

Adroher, Miquel, 2005-06: «La Stòria del Sant Grasal, version franciscaine de la Queste del Saint Graal», Butlletí de la Reial Acadèmia de Bones Lletres de Barcelona, 50, 77-119.

Alvar, Carlos, 2002: «Raíces medievales de los libros de caballerías», Edad de Oro, 21, 61-84.

Alvar, Carlos i José Manuel Lucía MegíAs, 1999: «Hacia el códice del Tristán de Leonís. Cincuenta y nueve nuevos fragmentos manuscritos en la Biblioteca Nacional de Madrid»), Revista de Literatura Medieval, 11, 9-135.

Aramon I Serra, Ramon (ed.), 193033: Curial e Güelfa, Barcelona: Barcino, 3 vols.
Aramon I Serra, Ramon, 1969: «El Tristany català d'Andorra», Mélanges offerts à Rita Lejeune, I, Gémbloux: J. Duculot, 323-37. Reproduiit dins R. Aramon i Serra, Estudis de llengua i literatura, ed. J. Carbonell, Barcelona: Institut d'Estudis Catalans, 1997, 413-29.

BADIA, Lola i Jaume Torró (eds.), en premsa: Curial e Güelfa, Barcelona: Quaderns Crema.

Bohigas, Pedro, 1929: «[Ressenya a:] El Cuento de Tristán de Leonís. -Edited from the unique manuscript, Vatican 6428 , by George Tyler Northup. -The University of Chicago Press, 1928, 298 págs. 4. (The Modern Philology Monographs)», Revista de Filología Española, 284-9.

BohIgAs, Pere, 1982: «La Matière de Bretagne en Catalogne», Bulletin Bibliographique de la Société Internationale Arthurienne, 13, 1961, 81-98. Repr., en versió catalana, «La matèria de Bretanya a Catalunya», Aportació a l'estudi de la literatura catalana, Barcelona: Publicacions de l'Abadia de Montserrat, 277-94.

BoHIgAs, Pere, 1962: «Un nou fragment del Lançalot català», Estudis Romànics, 10, 179-87.

Bonilla y San Martín, Adolfo, 1904: «Fragmento de un Tristán castellano del siglo XIV», Anales de Literatura Española (años 19001904), 25-8. 
BONNER, Anthony i Lola BADIA, 1988: Ramon Llull. Vida, pensament i obra literària, Barcelona: Empúries.

Casacuberta, Josep M. (ed.), 192752: Ramon Muntaner, Crònica, Barcelona, Barcino.

Cingolani, Stefano M., 1990-91: «'Nos en leyr tales libros trobemos plazer e recreation.' L'estudi sobre la difusió de la literatura catalana d'entreteniment a Catalunya els segles XIV i Xv»», Llengua \& Literatura, 4. 39-127.

Cingolani, Stefano M., 1992-93: «The Sirventes-ensenhamen of Guerau de Cabrera: A Proposal for a New Interpretation», Journal of Hispanic Research, 1, 191-201.

Cingolani, Stefano M., 2006: Historiografia, propaganda i comunicació al segle XIII: Bernat Desclot i les dues redaccions de la seva crònica, Barcelona, Institut d'Estudis Catalans.

Cingolani, Stefano M. (ed.), 2010: Bernat Desclot, Llibre del rei En Pere, Barcelona, Barcino.

Crescini, Vicenzo i Venanzio Todesco, 1917: La versione catalana della Inchiesta del san Graal secondo il codice dell'Ambrosiana di Milano I. 79 Sup., Barcelona: Institut d'Estudis Catalans.

Cuesta Torre, María Luzdivina, 1994: Aventuras amorosas y caballerescas en las novelas de Tristán, Lleó: Univ. de León, Secretariado de Publicaciones.

Cuesta Torre, María Luzdivina (ed.), 1999: Tristán de Leonís: Valladolid, Juan de Burgos, 1501, Alcalá de Henares: Centro de Estudios Cervantinos.

Duran I Sanpere, Agustí, 1917a: «Un fragment de Tristany de Leonis en català», Estudis Romànics, 9, 284-316.

Duran I SANPere, Agustí, 1917b: «Notícia de llibres en inventaris de Cervera»,
Butlletí de la Biblioteca de Catalunya, 4, 127-35.

ENTWISTLE, William J., 1925: The Arthurian Legend in the Literatures of the Spanish Peninsula, Londres: Dent. Reimpr. Nova York: Phaeton Press, 1975 .

IRAGUI, Sebastian, 1996: «The southern version of the Prose Tristan. The Italo-Iberian translations and their French source», Tristania, 17, 39-54.

LIDA de Malkiel, María Rosa, 1959: «Arthurian literature in Spain and Portugal», Arthurian Literature in the Middle Ages. A Collaborative History, ed. R. S. Loomis, Oxford: Clarendon, 406-18.

LÖSETH, E., 1891: Le Roman en prose de Tristan, le roman de Palamèdes et la compilation de Rusticien de Pise. Analyse critique d'après les manuscrits de Paris, París: Bouillon. Reimpr. Nova York: Burt Franklin, 1970.

Lucía Megías, José Manuel, 2005: «Literatura caballeresca catalana: de los testimonios a la interpretación (Un ensayo de crítica ecdótica)», Caplletra, 39 (tardor), 231-56.

MAs, Joseph, 1915-16: «Notes documentals de llibres antichs a Barcelona», Butlletí de la Reial Acadèmia de Bones Lletres de Barcelona, 8, 155-67, 238-51, 330-45, 400-6, 444-63.

PArodi, E. G. (ed.) 1869: Tristano Riccardiano, Parma: Pratiche, 1991.

Polidori, Filippo-Luigi (ed.), 1864: Tavola Ritonda o L'historia de Tristano, Bolonya: Gaetano Romagnoli.

Pujol, Josep, 2002a: «De Pere el Gran a Tristany de Leonís: models cronístics i novellescos per a la mort de Tirant lo Blanc»,, Literatura i cultura a la Corona d'Aragó (s. XIII-XV), ed. L. Badia, M. Cabré i S. Martí, Barcelona: Curial-Publicacions de l'Abadia de Montserrat, 409-18.
Pujol, Josep, 2002b: La memòria literària de Joanot Martorell. Models i escriptura en el «Tirant lo Blanc», Barcelona: Curial-Publicacions de l'Abadia de Montserrat.

Ramos, Rafael, 1995: «Tirant lo Blanc, Lancelot du Lac y el Llibre de l'orde de cavalleria», La Corónica, 23.2, 74-87.

Riquer, Martí de, 1985: Història de la literatura catalana. Part antiga (1964), Barcelona: Ariel, 4 vols.

Ros Domingo, Enrique Andrés, 2001: Arthurische Literatur der Romania. Die Iberoromanischen fassungen des Tristanromans und Ihre beziehungen zu den französischen und italianischen Versionen, Berna: Peter Lang.

Rubió I BALAGUeR, Jordi, 1984: Història de la literatura catalana, I, Barcelona: Publicacions de l'Abadia de Montserrat. Ed. original dins Historia general de las literaturas hispánicas, I, Desde los orígenes hasta 1400, dir. Guillermo Díaz-Plaja, Barcelona: Barna, 1949, 643-779.

Rubió I Lluch, Antoni, 1903: «Notícia de dos manuscrits d'un Lançalot català», transcr. de Mateu Obrador Revista de Bibliografia Catalana, 3, 6, 5-25.

RUBIÓ I LLUCH, Antoni, 1908-21: Documents per a la història de la cultura catalana medieval, Barcelona: Institut d'Estudis Catalans, 2000, 2 vols.

SANTANACH SUÑOL, Joan, 2002: «Literatura, ciència i història a l'Andorra medieval. Apunts sobre el Còdex miscellani de l'Arxiu Històric»», Ex-libris Casa Bauró, 5, 16-19.

SANTANACH SUÑOL, Joan, 2002): «Un notari andorrà de final del segle $x v$, lector de Ramon Llullı, Studia Lulliana, 42, 49-56.

SANTANACH SuÑol, Joan, 2003: «El Còdex miscellani de l'Arxiu de les Set Claus (Andorra la Vella, Arxiu Històric Nacional)», Anuario de Estudios Medievales, 33.1, 417-62. 
ShARRER, Harvey L., 1979: «Malory and the Spanish and Italian Tristan texts: The Search for the missing link»», Tristania, 4, 2 (maig), 36-43.

Soler, Albert (ed.), 1988: Ramon Llull, Llibre de l'orde de cavalleria, Barcelona: Barcino.

Soler, Albert i Joan SANTANAch (eds.), 2009: Ramon Llull, Romanç d'Evast e Blaquerna, Palma: Patronat Ramon Llull.

SORIANO Robles, Lourdes, 1999: «Els fragments catalans del Tristany de Leonís», Actes del VII Congrés de I'Associació Hispànica de Literatura Medieval (Castelló, 1997), ed. S. Fortuño Llorens i T. Martínez Romero, Castelló de la Plana: Univ. Jaume I, III, 413-28.

Soriano Robles, Lourdes, 2001: «'E que le daria ponçoña con que el muriese': los tres intentos de envenenamiento de Tristán a manos de su madrastra», Cultura Neolatina, 61.3-4, 319-33.

Tyler Northup, George (ed.), 1928: El Cuento de Tristan de Leonis. Edited from the Unique Manuscript Vatican 6428, Chicago: The University of Chicago Press.

Valls I SUbIRÀ, Oriol, 1970: Paper and Watermarks in Catalonia I El papel y sus filigranas en Catalunya, Amsterdam: The Paper Publications Society (Labarre Foundation), 2 vols.

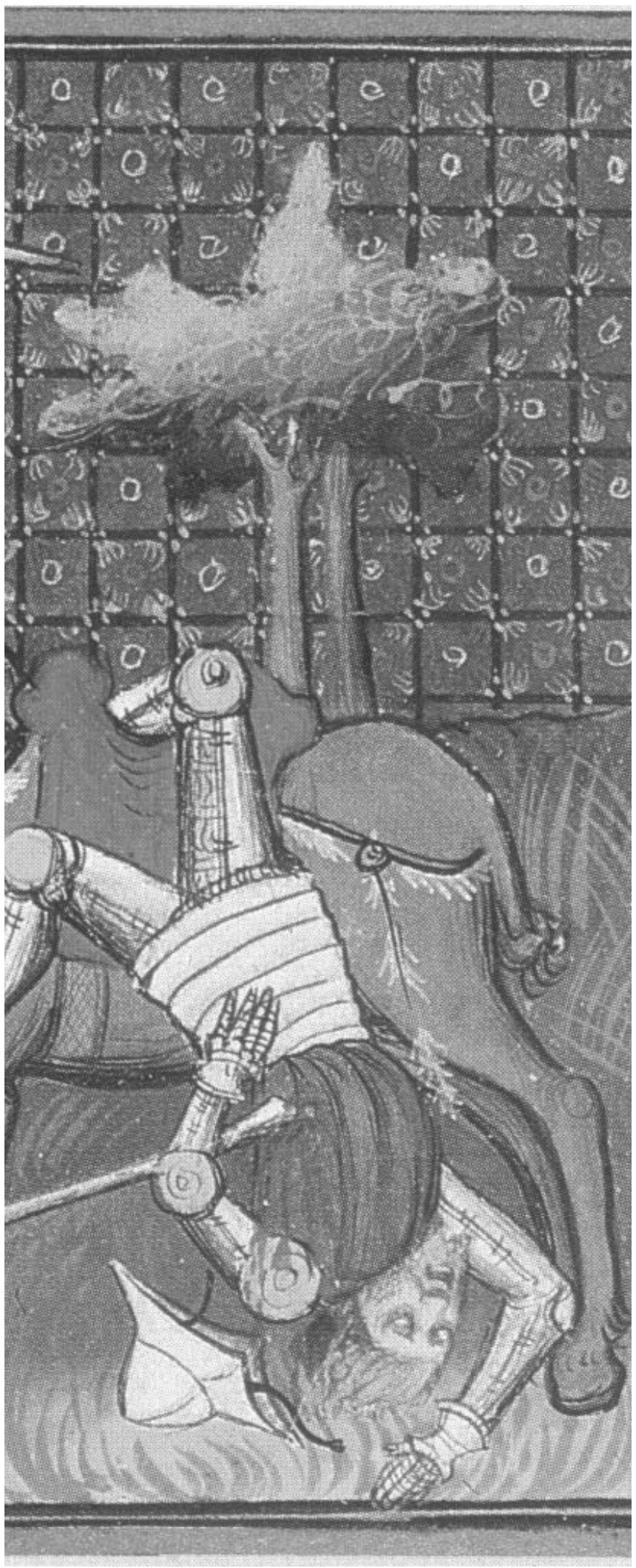

